\title{
Selection index for identifying high-yielding groundnut genotypes in irrigated and rainfed environments
}

\author{
By S CHANDRA ${ }^{1 *}, \mathrm{~S}^{\mathrm{N}}$ NIGAM$^{1}$, A W CRUICKSHANK ${ }^{2}$, A BANDYOPADHYAYA ${ }^{3}$ \\ and $S$ HARIKRISHNA
}

\author{
${ }^{1}$ International Crops Research Institute for the Semi-Arid Tropics, Patancheru 502 324, Andhra \\ Pradesh, India \\ ${ }^{2}$ Farming Systems Institute, Queensland Department of Primary Industries, $P$ O Box 23, Kingaroy \\ Q4610, Australia \\ ${ }^{3}$ National Research Centre for Groundnut (NRCG), Indian Council of Agricultural Research, PB No. \\ 5, Ivanagar Road, Junagadh 362 001, Gujarat, India
}

(Accepted 13 May 2003; Received 5 August 2002)

\begin{abstract}
Summary
Selection of high yielding genotypes to be carried over to subsequent selection cycles in a breeding programme can sometimes be accomplished using a suitable index of secondary traits that may be relatively less sensitive to genotype-by-environment interactions than yield. We used the concept of correlated response to selection to measure the relative efficiency of nine selection indices. The results showed that the selection index, based on median and semi inter-quartile range, which was actually used in identifying high yielding genotypes, had an efficiency that is comparable to the best index, the latter being a modification of the Elston index.
\end{abstract}

Key words: Groundnut, selection index, indirect selection, correlated response to selection

\section{Introduction}

Breeding programmes attempt to achieve genetic progress through sequential selection of high performance genotypes over a number of selection cycles. For traits such as yield that are highly influenced by genotype-by-environment interactions, the outcome of such a procedure remains highly unpredictable. Identification of high performance genotypes in a given cycle/generation can sometimes be more accurately done indirectly on the basis of other associated traits that are less sensitive to environmental variations. These associated traits, rather than being used individually, could be combined into a suitable index that could be used to identify high performance genotypes. The objective of this paper is to investigate the suitability of a selection index (S7 described later) and to compare its performance with other indices for reliable indirect selection of high-yielding genotypes. Each selection index was constructed from three traits: harvest index $(\mathrm{HI})$, transpiration efficiency (TE), and total transpiration (T), which are components of a biological model for seed yield (Passioura, 1986). These traits interact to determine final seed yield. Enough genetic variation exists for these traits in groundnut but some of these are not easy to measure in a large-scale breeding programme. However, easily measurable surrogate traits, particularly for TE, such as leaf carbon isotope discrimination, specific leaf area, and SPAD chlorophyll meter reading help to overcome this problem (Wright \& Nageswara Rao, 1994; Nageswara Rao et al., 2001).

\section{Material and Methods}

\section{Genetic Materials}

The genetic material consisted of 192 genotypes originating from four collaborating research centres in India, namely, the International Crops Research Institute for the Semi-Arid Tropics (ICRISAT) at Patancheru in Andhra Pradesh (AP), the Oilseeds Research Station of Mahatma Phule Krishi Vidyapeeth (MPKV) at Jalgaon in Maharashtra, the National Research Centre for Groundnut (NRCG) at Junagadh in Gujarat, and the Regional Agricultural Research Station of Acharya NG Ranga Agricultural University (ANGRAU) at Tirupati in AP. Each centre made four crosses in 1997, three crosses being common across centres. The fourth cross was centre specific. All four crosses at each centre were simultaneously advanced to further generations following a common selection scheme described below.

The $\mathrm{F}_{2}$ population of each cross at each centre was divided into two equal parts, each containing about 500 plants, for carrying out trait-based (S) and empirical (E) selection in 1998. For each selection method in each cross, $500 \mathrm{~F}_{2: 3}$ families constituted 
the base population. For selection method S, observations on $\mathrm{HI}$, TE, and T were recorded on 10 plants randomly selected from each $\mathrm{F}_{2: 3}$ family grown under no-moisture-stress conditions. These three traits were combined into a selection index S7 (described later) giving equal weight to each trait. The reason to choose the index S7 was that it, being based on median and semi-inter-quartile range, provided assurance that selection would not be influenced by extreme values in any trait. Also, at this stage, we had no hard data to compare the performance of alternative indices in order to choose a better index. The index S7 was used to select the top $10 \%$ of the $\mathrm{F}_{2: 3}$ families to get $50 \mathrm{~F}_{2: 4}$ families in each cross. Under selection method $\mathrm{E}$, selection of the top $10 \% \mathrm{~F}_{2: 3}$ families, also grown under nomoisture-stress conditions, was based directly on pod yield to generate $50 \mathrm{~F}_{2: 4}$ families.

The $50 \mathrm{~F}_{2: 4} \mathrm{~S}$-based families were grown under no-moisture-stress as well as under managed moisture-stress conditions. The $50 \mathrm{~F}_{2: 4}$ E-based families were grown under no-moisture-stress and rainfed conditions, the latter as per practice for drought resistance breeding at individual centres. Using the $\mathrm{S} 7$ index, the top $5(10 \%) \mathrm{F}_{2: 4}$ families were selected to generate $5 \mathrm{~F}_{2: 5}$ families under each growing condition for each selection method. These selected $\mathrm{F}_{2: 5}$ families were further evaluated under both selection methods and their seed increased. The replicated field trial in 2000 conducted at ICRISAT Patancheru consisted of $\mathrm{F}_{2: 6}$ families, three from nomoisture-stress and three from managed-moisturestress for selection method $\mathrm{S}$, and six from selection method $\mathrm{E}$ for each cross. The trial thus had 192 families [ $6 \mathrm{~S}$-based +6 E-based) families $\times 4$ crosses $\times 4$ centres]. The 192 genotypes were laid out in a 4 $\times 48$ alpha design with three replications.

\section{Selection indices}

Nine selection indices, as defined below, were investigated:

$$
\begin{aligned}
& \mathrm{S} 1=\sum_{\mathrm{j}}\left(\mathrm{x}_{\mathrm{j}}-\mathrm{m}_{\mathrm{j}}\right) / \mathrm{s}_{\mathrm{j}} \\
& \mathrm{S} 2=\sum_{\mathrm{j}}\left[\ln \left(\mathrm{x}_{\mathrm{j}}\right)-\mathrm{m}\left\{\ln \left(\mathrm{x}_{\mathrm{j}}\right)\right\}\right] / \mathrm{s}\left\{\ln \left(\mathrm{x}_{\mathrm{j}}\right)\right\} \\
& \mathrm{S} 3=\prod_{\mathrm{j}}\left(\mathrm{x}_{\mathrm{j}}-\mathrm{m}_{\mathrm{j}}\right) / \mathrm{s}_{\mathrm{j}} \\
& \mathrm{S} 4=\prod_{\mathrm{j}}\left[\ln \left(\mathrm{x}_{\mathrm{j}}\right)-\mathrm{m}\left\{\ln \left(\mathrm{x}_{\mathrm{j}}\right)\right\}\right] / \mathrm{s}\left\{\ln \left(\mathrm{x}_{\mathrm{j}}\right)\right\} \\
& \mathrm{S} 5=\prod_{\mathrm{j}} \ln \left(\mathrm{x}_{\mathrm{j}}-\mathrm{k}_{\mathrm{j}}\right), \mathrm{k}_{\mathrm{j}}=\left(\mathrm{n} * \min _{\mathrm{j}}-\max _{\mathrm{j}}\right) \text { (Elston, 1963) } \\
& \mathrm{S} 6=\prod_{\mathrm{j}}\left(\mathrm{x}_{\mathrm{j}}-\mathrm{k}_{\mathrm{j}}\right), \mathrm{k}_{\mathrm{j}}=\left(\mathrm{n} * \min _{\mathrm{j}}-\max _{\mathrm{j}}\right) \text { (modified Elston } \\
& \text { index })
\end{aligned}
$$

$$
\begin{aligned}
& \mathrm{S} 7=\sum_{\mathrm{j}}\left(\mathrm{x}_{\mathrm{j}}-\operatorname{med}_{\mathrm{j}}\right) / \mathrm{SIQR}_{\mathrm{j}}, \mathrm{SIQR}_{\mathrm{j}}=\left\{\mathrm{Q}_{3(\mathrm{j})}-\mathrm{Q}_{1(\mathrm{j})}\right\} / 2 \\
& \mathrm{~S} 8=\sum_{\mathrm{j}}\left(\mathrm{x}_{\mathrm{j}}-\operatorname{med}_{\mathrm{j}}\right) / \mathrm{R}_{\mathrm{j}}, \mathrm{R}_{\mathrm{j}}=\max _{\mathrm{j}}-\min _{\mathrm{j}}
\end{aligned}
$$

$\mathrm{S} 9=\left[\left(\mathrm{x}_{1}-\mathrm{m}_{1}\right) / \mathrm{s}_{1}\right]-\left[\left(\mathrm{x}_{2}-\mathrm{m}_{2}\right) / \mathrm{s}_{2}\right]+\left[\left(\mathrm{x}_{3}-\mathrm{m}_{3}\right) / \mathrm{s}_{3}\right]$

where, for trait $\mathrm{j}\left(\mathrm{j}=1,2,3 ; \mathrm{x}_{1}=\right.$ harvest index, $\mathrm{x}_{2}=$ transpiration efficiency, $x_{3}=$ total transpiration), $x_{j}$ is the phenotypic value of an individual for trait $\mathrm{j}$, $\mathrm{m}_{\mathrm{j}}$ is the mean performance of all individuals for trait $\mathrm{j}, \mathrm{s}_{\mathrm{j}}$ is the standard deviation for trait $\mathrm{j}$, ln stands for natural logarithm, med stands for median, $Q_{1(j)}$ and $\mathrm{Q}_{3(\mathrm{j})}$ are the first and third quartiles of trait $\mathrm{j}$.

\section{Measurement of selection efficiency}

The relative selection efficiency (RSE) of an index $S$ relative to direct selection based on yield $\mathrm{Y}$ was measured as the ratio of correlated (CR) to direct response (R) to selection as follows (Bos \& Caligari, 1995)

$\mathrm{RSE}_{\mathrm{S}}=\mathrm{CR}_{\mathrm{Y}} / \mathrm{R}_{\mathrm{Y}}$

where

$\mathrm{CR}_{\mathrm{Y}}=\mathrm{i}_{\mathrm{S}} \quad \mathrm{r}_{\mathrm{G}} \mathrm{h}_{\mathrm{S}} \sigma_{\mathrm{G}(\mathrm{Y})}$

is the correlated response to selection,

$\mathrm{R}_{\mathrm{Y}}=\mathrm{i}_{\mathrm{Y}} \mathrm{h}_{\mathrm{Y}} \sigma_{\mathrm{G}(\mathrm{Y})}$

is the direct response to selection, $\mathrm{i}_{\mathrm{S}}$ and $\mathrm{i}_{\mathrm{Y}}$ are selection intensities for $\mathrm{S}$ and $\mathrm{Y}, \mathrm{h}_{\mathrm{S}}$ and $\mathrm{h}_{\mathrm{Y}}$ are square root of heritabilities of $S$ and $Y, r_{G}$ is the genetic correlation between $\mathrm{S}$ and $\mathrm{Y}$, and $\sigma_{\mathrm{G}(\mathrm{Y})}$ is the genetic standard deviation of $\mathrm{Y}$. It was assumed that $\mathrm{i}_{\mathrm{S}} \approx \mathrm{i}_{\mathrm{Y}}$, which reduces equation (1) to

$\operatorname{RSE}_{\mathrm{S}}=\mathrm{r}_{\mathrm{G}}\left(\mathrm{h}_{\mathrm{S}} / \mathrm{h}_{\mathrm{Y}}\right)$

Thus, for indirect selection for $Y$ through $S$ to be superior, $\left|\mathrm{r}_{\mathrm{G}}\right|>\mathrm{h}_{\mathrm{Y}} / \mathrm{h}_{\mathrm{S}}$ which implies that $\mathrm{h}_{\mathrm{Y}}<\left|\mathrm{r}_{\mathrm{G}} \mathrm{h}_{\mathrm{S}}\right|$, in order to obtain $\mathrm{RSE}_{\mathrm{S}}>1$.

\section{Statistical analysis}

Plot-wise data for each index was generated, based on the definition of the index given earlier. Assuming genotype effects as random, the restricted maximum likelihood (ReML) procedure in GenStat statistical computing software was used to obtain the best linear unbiased prediction (BLUP) of genotype performance, and unbiased estimates of genetic variance $\sigma_{\mathrm{G}}{ }^{2}$ and error variance $\sigma_{\mathrm{e}}{ }^{2}$ for $\mathrm{Y}$ and index S. Heritability on entry-mean-basis was computed as

$\mathrm{h}^{2}=\sigma_{\mathrm{G}}{ }^{2} /\left\{\sigma_{\mathrm{G}}{ }^{2}+\left(\sigma_{\mathrm{e}}^{2} / \mathrm{r}\right)\right\}$

where $r=3$ is the number of replications. Genetic correlation $\mathrm{r}_{\mathrm{G}}$ between $\mathrm{Y}$ and $\mathrm{S}$ was computed as

$\mathrm{r}_{\mathrm{G}}=\sigma_{\mathrm{G}(\mathrm{Y}, \mathrm{S})} /\left\{\sigma_{\mathrm{G}(\mathrm{Y})} \sigma_{\mathrm{G}(\mathrm{S})}\right\}$ 
where $\sigma_{\mathrm{G}(\mathrm{Y}, \mathrm{S}) \text {, }}$ the genetic covariance between $\mathrm{Y}$ and $\mathrm{S}$, was computed as

$\sigma_{\mathrm{G}(\mathrm{Y}, \mathrm{S})}=(1 / 2)\left[\sigma_{\mathrm{G}(\mathrm{Y}+\mathrm{S})}^{2}-\left\{\sigma_{\mathrm{G}(\mathrm{Y})}^{2}+\sigma_{\mathrm{G}(\mathrm{S})}^{2}\right\}\right]$

which was derived from the standard formula

$\sigma_{\mathrm{G}(\mathrm{Y}+\mathrm{S})}^{2}=\sigma_{\mathrm{G}(\mathrm{Y})}^{2}+\sigma_{\mathrm{G}(\mathrm{S})}^{2}+2 \sigma_{\mathrm{G}(\mathrm{Y}, \mathrm{S})}$

for variance of the sum of two random variables $Y$ and $\mathrm{S}$.

\section{Results and Discussion}

Results are summarised in Tables 1 and 2 for adjusted kernel weight and Tables 3 and 4 for adjusted pod weight under irrigated (IR) and rainfed (RF) environments. RSE under RF is observed to be higher than that under IR for all indices, except S3 and S4. RSE under IR for all indices is $<1$, implying that direct selection using $\mathrm{Y}$ is expected to be superior under IR. Under RF, only S6 and S9 have $\mathrm{RSE}>1$. These two indices also have the highest RSE values under IR though always $<1$. To verify the RSE-based performance of various indices, the top 20 genotypes (approximately 10\% of total 192 genotypes) for each index were identified and compared with the top 20 genotypes for yield. The results are presented in Tables 1-4.

\section{Adjusted kernel weight}

Under IR (Table 1), the indices S1, S2, S7 and S8, irrespective of their RSE values, generally identified the top 10 entries amongst their top 20 ones. With respect to the identification of the number of top 20 entries, index S6, having the highest RSE $<1$, performed the best in identifying the 16 top entries but did not include the best-yielding entry. This was followed by indices S1 and S2 which identified the 15 top entries, and S7 and S8 which identified the 14 top entries each, despite the fact that they had $\mathrm{RSE}<1$. Each of these four indices also correctly identified the two best-yielding entries. Index S9, having RSE very close to index S6, performed very poorly, with only the five best yielding genotypes identified among its top 20 entries. Indices S3, S4, and S5 performed the worst, the first two having a negative genetic correlation with yield, and S5 having a very low RSE of 0.216 .

Under RF (Table 2), the results are nearly similar to those in IR except that S6, having RSE $=1.076$, delivered an excellent performance with 18 out of its top 20 entries correctly identified which also included the best one, two, five, and 10 entries. This was followed by indices S2, S1, S7, and S8 which, respectively, identified the top $16,15,14$, and 14 entries, including the best one, two, and five entries, despite their RSE being $<1$. The most unsatisfactory performance was that of S9 which, despite having an RSE similar to S6, could identify only five top yielding genotypes in its top 20 entries.

\section{Adjusted pod weight}

Under IR (Table 3), results are more or less similar to adjusted kernel weight (Table 1). The indices $\mathrm{S} 1$, $\mathrm{S} 2$ and $\mathrm{S} 7$, each having RSE $<1$, correctly identified the best one, two, five, and 10 top yielding genotypes in their top 10 entries, but their performance declined when it came to identifying the top 15 and 20 entries. The best performance was delivered by $\mathrm{S} 2$, followed by S1, S7, S8 and S6. Index S9, having the highest $\mathrm{RSE}<1$, performed very poorly.

Under RF (Table 4), indices S1, S2, S6, S7 and S8 correctly identified the best one, two, and five top yielding genotypes in their top five entries, though only S6 had RSE > 1. Index S6 gave the best performance in selecting the top 17 in its top 20 entries, followed by indices S2, S1, S7, S8, S9. Index S9 having the highest RSE $>1$ again performed very poorly.

In summary, if we consider simultaneously both the RSE and the number of correctly identified top yielding genotypes, there is no single index that seems to be consistently superior under IR across the two traits (adjusted kernel weight and adjusted pod weight). Index S6 was the best for adjusted kernel weight but excluded the highest yielding genotype and index S2 performed the best for adjusted pod weight. However, the performance of index S7, which was used to generate the 192 genotypes, was reasonably comparable with these two indices, with the best, the top two, the top five and the top 10 genotypes being correctly identified. Under RF, the index S6 consistently performed the best across the two traits, with performance of index $\mathrm{S} 7$ being reasonably close. It thus seems that the use of index S6 under RF would have resulted in a higher response to selection than the index S7 that we used. However, in view of the comparable performance of index S7, the use of index S6 would have not made a substantial difference.

\section{Acknowledgements}

This work forms part of the Australian Centre for International Agricultural Research (ACIAR) Project \# CS 1/1997/114, 'More efficient breeding of drought resistant peanuts in India and Australia'. We thank all project scientists in Australia and India, specially Drs G C Wright and Nageswara Rao Rachaputi, QDPI, Australia, Drs P V Reddy and R P Vasanthi, RARS, ANGRAU, Tirupati, and Dr M P Deshmukh, Oilseeds Research Station, MPKV, Jalgaon, who, on various occasions and discussions, provided useful suggestions to the authors. 


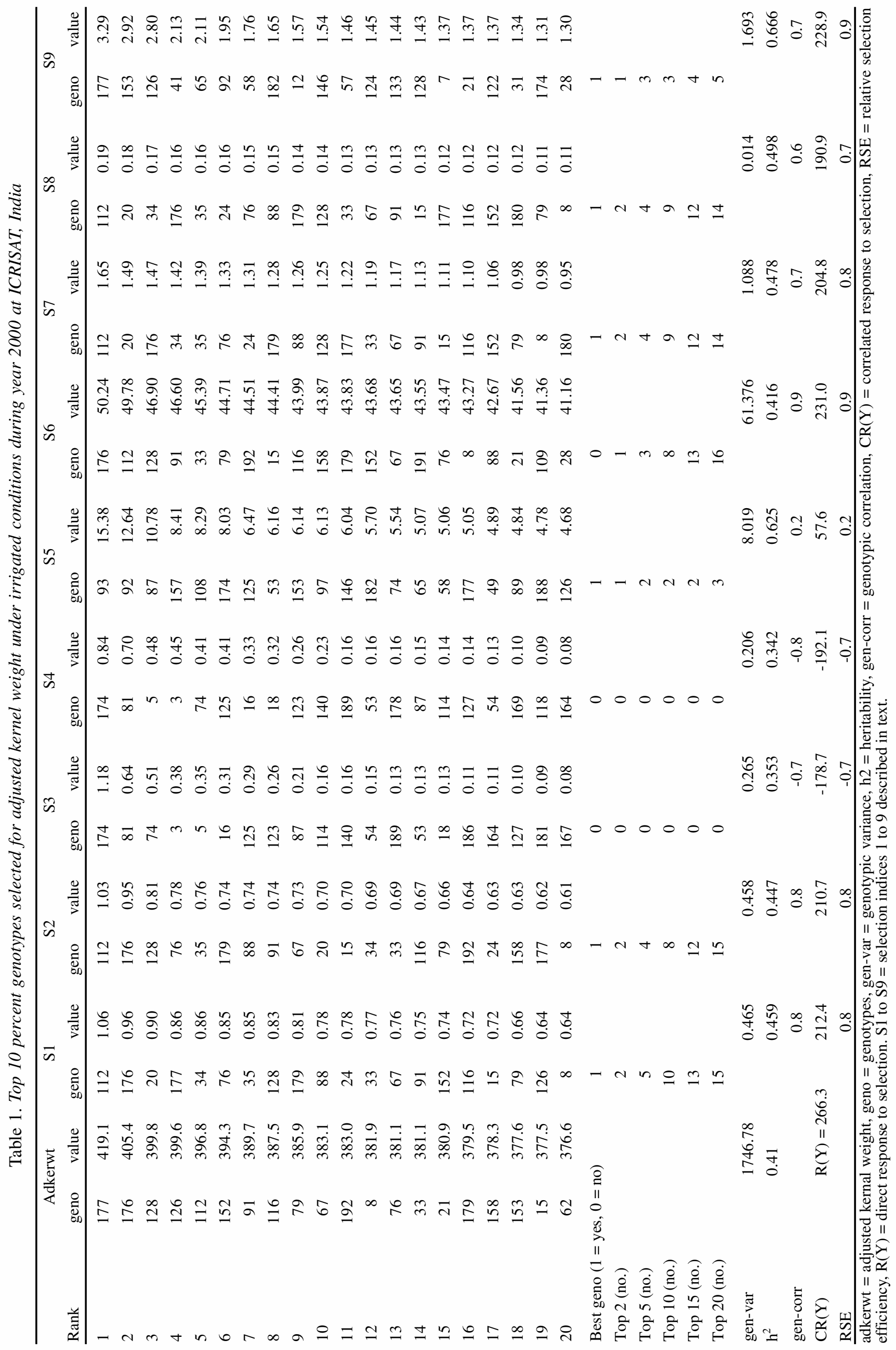




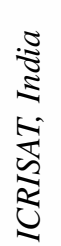
8

$\underset{8}{8}$

$\infty$

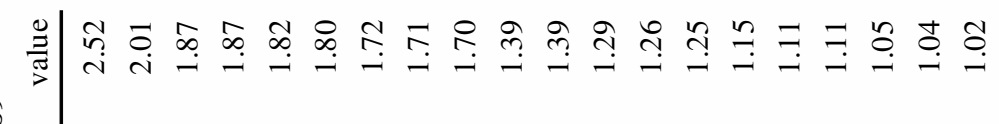

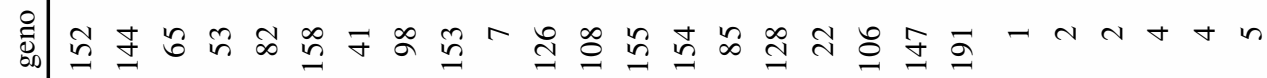

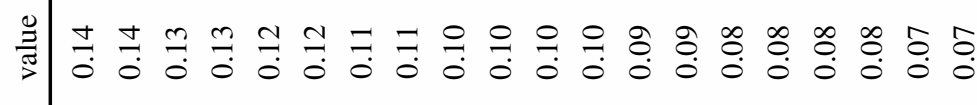

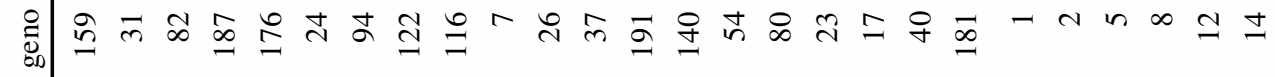

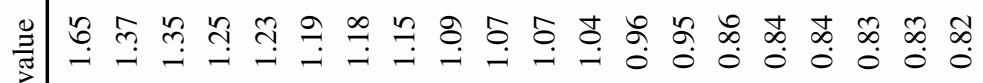

is

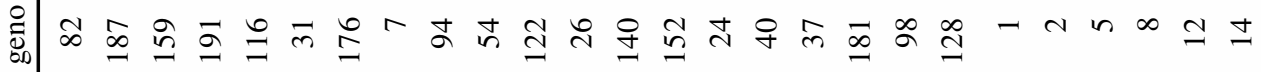

๑) ๆิ ๆ ๆ

可

i

임

๖

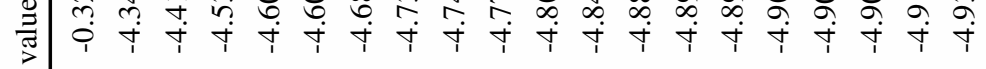

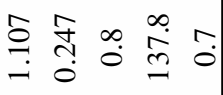

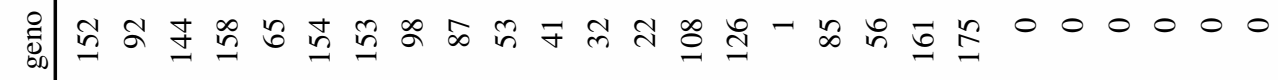

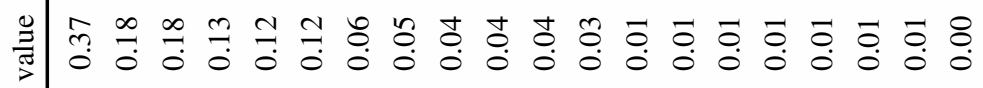

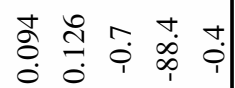

is

苛

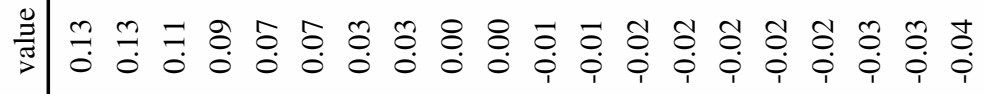

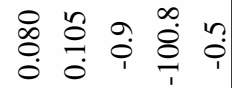

总

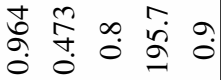

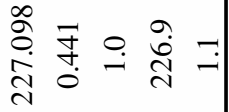

帝

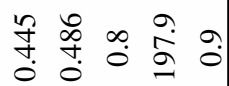

摛

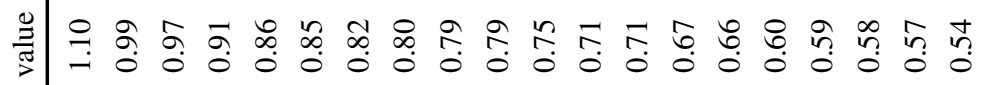

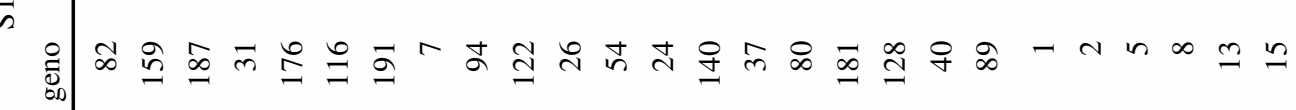

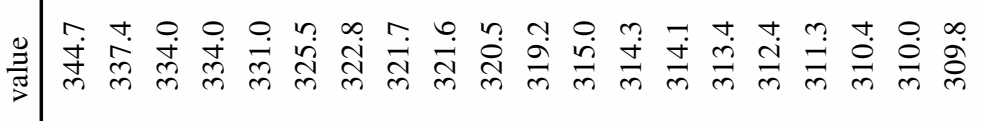




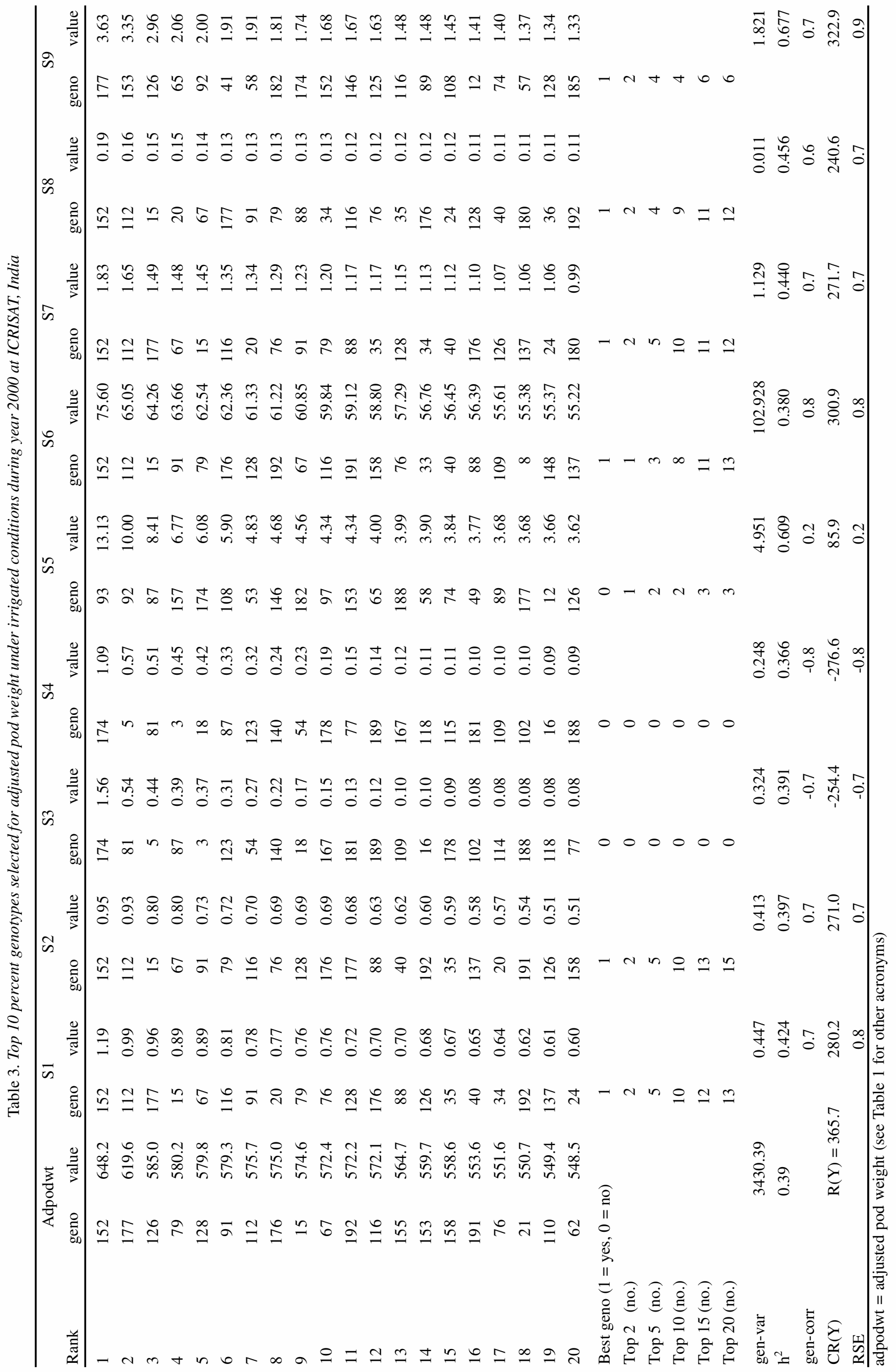




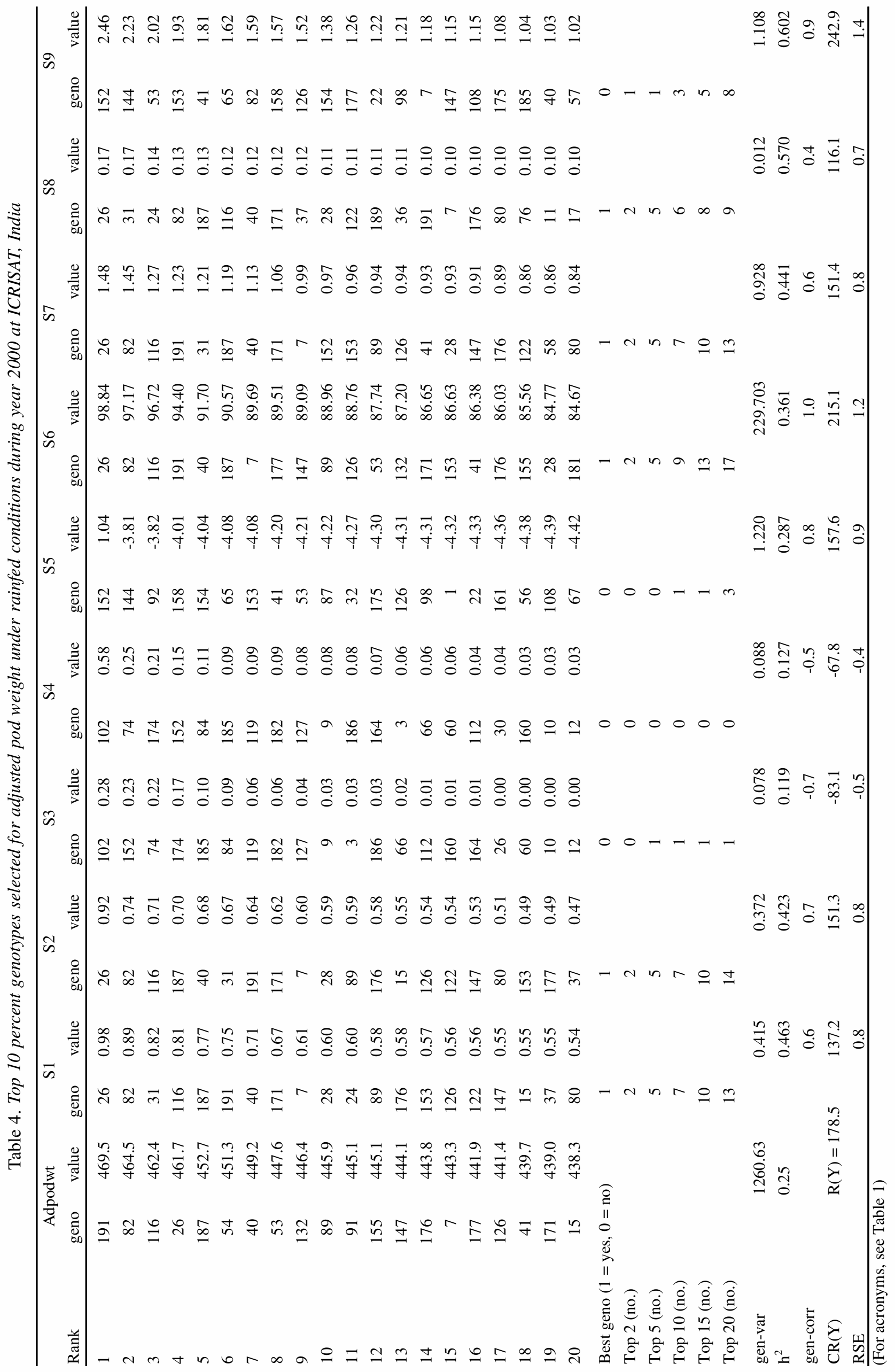




\section{References}

Bos I, Caligari P. 1995. Selection Methods in Plant Breeding. London: Chapman \& Hall Ltd. 347 pp.

Elston R C. 1963. A weight-freeindex for the purpose of ranking or selection with respect to several traits at a time. Biometrics 19:85-97.

Nageswara Rao R C, Talwar H S, Wright G C. 2001. Rapid assessment of specific leaf area and leaf nitrogen in peanut (Arachis hypogaea L.) using a chlorophyll meter. Jornal of Agronomy and Crop Science 186:175-182.
Passioura J B. 1986. Resistance to drought and salinity: avenues for improvement.Australian Journal of Plant Physiology 13:191-201.

Wright G C, Nageswara Rao R C. 1994. Carbon isotope discrimination, water-use efficiency, specific leaf area relationships in groundnut. In Selection for Water-Use Efficiency in Grain Legumes, pp. 52-58. Eds G C Wright and R C Nageswara Rao. Report of a workshop held at ICRISAT Centre, Andhra Pradesh, India, 5-7 May 1993. ACIAR Technical Reports No. 27.70 pp. 